\title{
IMITAR? DIFERENCIAR? CONTINUAR IGUAL? ESTRATÉGIAS DA ACADEMIA EDU'S PARA LIDAR COM A NOVA CONCORRENTE
}

\author{
IMITATE? DIFFERENTIATE? CONTINUE THE SAME WAY? STRATEGIES OF EDU'S GYM TO DEAL WITH \\ THE NEW COMPETITOR
}
¿IMITAR? ¿DIFERENCIAR? ¿SEGUIR IGUAL? ESTRATEGIAS DEL GIMNASIO EDU'S PARA ENFRENTAR A UN NUEVO COMPETIDOR

\author{
ALFREDO RIBEIRO CÁRDENAS \\ Mestre \\ Universidade do Estado de Santa Catarina - Brasil \\ alfredorcardenas@hotmail.com
}

ÉVERTON LUÍS PELLIZZARO DE LORENZI CANCELLIER

Doutor

Universidade do Estado de Santa Catarina - Brasil everton.cancellier@gmail.com

SIMONE GHISI FEUERSCHÜTTE

Doutor

Universidade do Estado de Santa Catarina - Brasil ghisi.simone@gmail.com

Submetido em: 02/04/2014

Aprovado em: 16/06/2015

Doi: alcance.v22n3.442-453

\section{RESUMO}

Eduardo é o proprietário de uma academia já estabelecida há anos na cidade e encontra-se em uma situação desconfortável diante da abertura de uma nova concorrente, praticamente em frente ao seu empreendimento. A nova academia promete oferecer diferenciais que o empreendimento de Eduardo não oferece - equipamentos mais modernos, horários mais atrativos e climatização. A mensalidade anunciada pela nova concorrente é praticamente equivalente à praticada na academia de Eduardo. Diante do cenário que está sendo criado, ele terá que encontrar estratégias para lidar com a nova concorrente e manter o seu empreendimento viável.

Palavras-chave: Estratégia. Estratégias genéricas. Visão Baseada em Recursos (VBR).

\begin{abstract}
Eduard is the owner of a gym that has been established in the town for years, but now finds himself in an uncomfortable situation, due to the opening of a new competitor practically opposite his establishment. The new gym promises to offer advantages that the Eduard's enterprise does not offer - more modern equipment, more attractive opening hours, and air conditioning. The monthly fee announced by the new competitor is the same as that practiced by Eduard's Gym. Faced with this scenario, he will need to find strategies to deal with the new competitor and ensure his business remains viable.
\end{abstract}

Keywords: Strategy. Generic Strategies. Resource Based View (RBV). 


\section{RESUMEN}

Eduardo es el propietario de un gimnasio ya establecido hace años en la ciudad y se encuentra en una situación incómoda ante la abertura de un nuevo competidor prácticamente en frente de su emprendimiento. El nuevo gimnasio promete ofrecer diferenciales que el emprendimiento de Eduardo no ofrece - equipos más modernos, horarios más atractivos y climatización. La mensualidad anunciada por el nuevo competidor es prácticamente equivalente a la cobrada en el gimnasio de Eduardo. Frente a ese escenario, Eduardo tendrá que encontrar estrategias para lidiar con el nuevo competidor y mantener viable su emprendimiento.

Palabras clave: Estrategia. Estrategias genéricas. Visión Basada en Recursos (VBR).

\section{INTRODUÇÃO}

É uma manhã agradável de primavera e Eduardo acordou um pouco mais tarde, ao contrário do que acontece durante os dias da semana, quando abre pontualmente, às 8h, a academia de médio porte da qual é proprietário, no centro da cidade.

Como hábito de todos os sábados, logo ao levantar se encaminha à caixa de correios para pegar a correspondência que acumulara ao longo da semana. Ao retornar e sentindo o aroma de café passado por sua esposa, Maria Rita, Eduardo separa as correspondências pessoais dos panfletos de propaganda em geral. Após deixar sobre a mesa as faturas do cartão de crédito, do carro importado e da faculdade de um dos filhos, Eduardo para com um encarte grande e chamativo nas mãos.

Pintado em preto e laranja e produzido em papel de primeira linha, o encarte, que destoava das demais propagandas, parecia até ter sido elaborado para anunciar um empreendimento imobiliário de alto padrão. A mensagem, no entanto, dizia: "A mais nova academia da região te espera com grandes atrações: equipamentos de última geração, horários aos finais de semana e CLIMATIZAÇAO!".

Eduardo estava surpreso, mas ficaria perplexo ao descobrir o valor da mensalidade proposto pela nova academia e, principalmente, o endereço do seu mais novo concorrente.

\section{A HISTÓRIA DE EDUARDO}

Eduardo, desde muito jovem, gostava de esportes. Na escola era destaque nos campeonatos de futebol e em sala de aula era bastante responsável com os estudos. Diante da afinidade com os esportes em geral e por demonstrar habilidade e empatia em suas relações interpessoais, não teve dúvidas na hora de escolher sua profissão. $O$ curso superior em Educação Física, concluído em uma universidade pública na capital do estado, era um dos mais concorridos e conceituados do país. Eduardo foi um dos primeiros colocados na lista de candidatos aprovados.

Muito feliz e animado com a sua primeira conquista - ingressar na universidade -, Eduardo mudou-se para a capital. Desde a viagem de mudança, planos e sonhos futuros já tomavam conta de seus pensamentos, entre eles o de ser um grande profissional da área e, quem sabe, abrir sua própria academia. Ele sabia que iria sentir saudades da família e dos amigos que ficariam no interior, mas tinha consciência de que quatro anos de estudo seriam importantes em sua formação profissional e amadurecimento pessoal.

Foi na faculdade que Eduardo conheceu Maria Rita. Por serem de cidades muito próximas e viajarem constantemente para visitar seus familiares, Edu - como era mais conhecido entre os colegas - e Maria Rita tornaram-se grandes amigos e depois namorados. $\mathrm{O}$ amor que teve início nos primeiros meses da faculdade foi oficializado um ano depois da formatura, quando Maria Rita, já grávida do primeiro filho, foi morar com Eduardo.

Nessa época, já de volta a sua cidade natal, Edu resolveu montar a academia que sonhava com o dinheiro de uma causa judicial recebida por seu pai. De acordo com seus cálculos, o dinheiro seria mais que suficiente para comprar os equipamentos da academia e reformar o espaço físico da sala comercial localizada muito próxima a casa onde moravam depois de casados. Eduardo pensava ainda que, sendo ele e a mulher formados em Educação Física, no início poderiam trabalhar na academia sem precisar contratar outros 
profissionais. Com o crescimento e a expectativa de sucesso do negócio, ele também imaginava que, ao longo dos anos, poderiam diminuir gradativamente o ritmo de trabalho e contratar outros profissionais para substituílos.

\section{O INÍCIO DA ACADEMIA DE EDUARDO}

O dinheiro do pai de Eduardo que, inicialmente, seria suficiente para montar a academia, na verdade quase que não supre o expressivo gasto com a construção dos vestiários, inexistentes na estrutura da sala comercial. A academia iniciou a prestação de serviços com uma ampla sala de musculação, e outra com esteiras, bicicletas e local para alongamento. A academia de Eduardo foi, então, batizada de Edu's.

No começo Eduardo passava em média 12 horas por dia na academia. Maria Rita trabalhava bem menos que Eduardo, pois tinha que cuidar do filho pequeno.

Ao contrário de boa parte dos novos empreendimentos, a Edu's não teve dificuldades de se estabelecer no mercado da região. Talvez por ter sido uma das primeiras academias da cidade e, principalmente, por estar muito bem localizada, no centro da cidade, logo após os primeiros meses o empreendimento atraiu clientela suficiente para cobrir seus custos. Com o resultado financeiro, Eduardo conseguia dar conta do aluguel da sala comercial, dos salários dos empregados (faxineira e recepcionista) e dos professores (o próprio Eduardo e sua esposa) e ainda guardar um pouco de dinheiro para eventual necessidade.

Passados três anos do negócio, já com o retorno do investimento, Eduardo decidiu pela ampliação da academia. A sala de ginástica, antiga reivindicação do público feminino, finalmente foi construída, juntamente com a remodelação da fachada da academia.

À época, Maria Rita, que já pensava em se afastar do trabalho por não se identificar tanto com esse ambiente quanto Eduardo, ficou novamente grávida e desligou-se do empreendimento.

\section{O CRESCIMENTO}

Ao longo dos anos a academia de Eduardo cresceu ainda mais. Não em termos de infraestrutura, mas principalmente no número de alunos e no reconhecimento na região. $O$ "Edu da academia" ficou conhecido em toda a cidade e arredores e até patrocina o time de futebol local.

Junto com a academia, o patrimônio de Eduardo também cresceu e a melhoria das condições de vida da família foi visível: casa de alto padrão; carro importado para ele e um popular para Maria Rita; aquisição de um terreno de esquina, também no centro da cidade, ainda sem construção.

É verdade que várias academias foram abertas após o surgimento da Edu's, mas não chegavam a incomodar o empreendimento de Eduardo, pois grande parte delas era de porte pequeno. Além disso, nenhuma academia instalou-se na região central da cidade - 0 investimento para abrir um negócio de tal natureza nas imediações da Edu's seria bastante alto.

Há dois anos, por ocasião do aniversário de 20 anos da academia, Eduardo promoveu uma grande comemoração. Convidou, além dos alunos, diversos amigos e conhecidos da cidade, aproveitando a festa para anunciar a reforma da academia, com a troca dos equipamentos da musculação por outros mais modernos, reduzindo-se a frequência de manutenção, segundo o fabricante. Os gastos para a realização da festa e a troca dos equipamentos foram elevados e muito questionados por Maria Rita. Eduardo, entretanto, entendia que a comemoração e a reforma eram investimento na academia, significando gratidão aos alunos pela fidelidade e também um meio de divulgar o empreendimento. Vale ressaltar que os gastos com a comemoração fizeram com que 0 caixa da empresa tivesse uma redução significativa (próximo a zero), sentindo-se 0 impacto nos seus resultados financeiros durante meses após o episódio.

As finanças voltaram ao equilíbrio no início da primavera daquele ano, quando a demanda de clientes aumentou em função da chegada do verão.

\section{ATUALMENTE}


Eduardo, atualmente com 47 anos, tem uma vida tranquila por consequência do sucesso de seu empreendimento ao longo do tempo. Embora se sinta um pouco desgastado com o dia a dia da academia trabalha em média 10 horas por dia, como professor de musculação e como coordenador -, sente-se realizado. Ele costuma dizer que "trabalha no que ama" e não se vê fazendo outra coisa na vida.

O filho mais velho de Eduardo, hoje com 21 anos, está prestes a concluir o curso de Administração na mesma universidade pública onde o pai se formou. É um ótimo aluno, se comunica em inglês com fluência e acaba de ser aprovado em um programa de trainee em uma multinacional. Ao contrário do pai, o primogênito de Eduardo não tem intenção de voltar para o interior. Já o filho mais novo mora em uma cidade vizinha e cursa Educação Física em uma faculdade privada da região. Com 20 anos, o caçula costuma dizer que quer trabalhar na academia do pai assim que se formar, o que deixa Eduardo contente e tranquilo, pois terá condições de, num futuro próximo, desligar-se aos poucos do trabalho técnico e dedicar-se à administração do seu empreendimento. Maria Rita, por sua vez, não atua mais como professora na academia, mas auxilia o marido nas tarefas administrativas da Edu's.

O empreendimento de Eduardo, atualmente, já não apresenta crescimento significativo tal como nos primeiros anos, mas continua com boa saúde financeira. Conta com um número considerável de clientes fiéis metade da sua clientela, 150 alunos - que frequentam a academia há mais de cinco anos. A receita gerada pelas mensalidades dos alunos é suficiente para custear despesas com a manutenção do empreendimento (custos fixos e variáveis) e ainda gera lucro. $O$ sustento da família de Eduardo e a manutenção de um bom padrão de vida advêm, exclusivamente, do lucro da academia.

Eduardo sempre se preocupou com a efetividade do sucesso de seu empreendimento e, por isso, ao longo dos últimos três anos, realizou pesquisas de satisfação junto a, pelo menos $90 \%$ de seus clientes. Os resultados das pesquisas demonstram que, em geral, os frequentadores da academia estão bastante satisfeitos com os serviços oferecidos. Os pontos fortes da Edu's identificados nos resultados das pesquisas são: a localização, o espaço físico, o atendimento prestado pelas três funcionárias da recepção e, principalmente, a qualidade dos oito professores da academia, dentre os quais, o próprio Eduardo.

Com o objetivo de acompanhar e analisar os resultados das pesquisas ao longo do tempo, Eduardo elaborou a Tabela 1.

Tabela 1: Resultado das pesquisas de satisfação dos clientes da Edu's

2011 a 2013

\begin{tabular}{c|c|c|c|c|c|c|c|c|c}
\cline { 2 - 10 } & \multicolumn{3}{c|}{$\mathbf{2 0 1 1}$} & \multicolumn{3}{c|}{$\mathbf{2 0 1 2}$} & \multicolumn{3}{c}{$\mathbf{2 0 1 3}$} \\
\hline Item avaliado & $\mathrm{R}$ & $\mathrm{M}$ & $\mathrm{B}$ & $\mathrm{R}$ & $\mathrm{M}$ & $\mathrm{B}$ & $\mathrm{R}$ & $\mathrm{M}$ & $\mathrm{B}$ \\
\hline Estrutura física & $2 \%$ & $15 \%$ & $83 \%$ & $1 \%$ & $14 \%$ & $85 \%$ & $2 \%$ & $14 \%$ & 84 \\
\hline Equipamentos & $4 \%$ & $7 \%$ & $89 \%$ & $6 \%$ & $10 \%$ & $84 \%$ & $6 \%$ & $16 \%$ & $\mathbf{7 8 \%}$ \\
\hline Atendimento recepção & $3 \%$ & $7 \%$ & $90 \%$ & $2 \%$ & $5 \%$ & $93 \%$ & $2 \%$ & $5 \%$ & $93 \%$ \\
\hline Qualidade professores & $1 \%$ & $4 \%$ & $95 \%$ & $1 \%$ & $1 \%$ & $98 \%$ & $0 \%$ & $2 \%$ & $98 \%$ \\
\hline Horários oferecidos & $5 \%$ & $10 \%$ & $85 \%$ & $7 \%$ & $12 \%$ & $81 \%$ & $9 \%$ & $15 \%$ & $76 \%$ \\
\hline Satisfação geral & $\mathbf{2} \%$ & $\mathbf{1 0} \%$ & $\mathbf{8 8} \%$ & $\mathbf{1} \%$ & $\mathbf{1 0} \%$ & $\mathbf{8 9} \%$ & $\mathbf{2} \%$ & $\mathbf{9 \%}$ & $\mathbf{8 9 \%}$ \\
\hline
\end{tabular}

Legenda: R- Ruim, M- Médio, B- Bom

Fonte: Edu's $(2011 ; 2012 ; 2013)$.

Apesar de o empreendimento apresentar um bom padrão de desempenho, segundo a ótica dos clientes nas pesquisas, os resultados demonstram também que alguns aspectos do serviço e da própria estrutura da academia podem ser aprimorados. Os clientes apontam, neste sentido, que seria necessário melhorar a climatização e modernizar os aparelhos, uma vez que a tecnologia e o mercado dos equipamentos esportivos e fitness estão em permanente evolução e sempre apresentam novidades que poderiam ser absorvidas pela 
Edu's. Parte dos clientes sugere, ainda, que a academia abra aos finais de semana. As demandas e as sugestões dos clientes da Edu's são apresentadas no Quadro 1.

Quadro 1: Principais sugestões dos clientes da academia

\begin{tabular}{|c|c|c|}
\hline 2011 & 2012 & 2013 \\
\hline & - Climatização & - Climatização \\
- Abrir aos finais de & - Abrir aos finais de \\
semana & - Abrir aos finais de & semana \\
& semana & - Equipamentos mais \\
& modernos \\
\hline
\end{tabular}

Fonte: Edu's $(2011 ; 2012 ; 2013)$.

Eduardo tem consciência das necessidades de seu empreendimento, mas entende que, para climatizar todo o ambiente e fazer renovações sistemáticas para modernizar os equipamentos de musculação, seria preciso um alto investimento, colocando em risco o caixa da empresa. Fazer um financiamento para suprir tais demandas diminuiria o lucro da academia e utilizar recursos da família não contaria com o de Maria Rita.

Diante de tudo isso, no segundo semestre de 2012 Eduardo realizou uma enquete com todos os clientes da Edu's para conhecer a real necessidade de climatização e de abertura da academia aos finais de semana. Os resultados do levantamento (Tabela 2) mostraram que uma parcela expressiva de alunos achava importante a academia ser climatizada e que abrisse aos finais de semana, mas apenas $30 \%$ estariam dispostos a assumir um aumento de mensalidade em troca destes benefícios.

Tabela 2: Enquete com os clientes sobre a importância das mudanças na Edu's

\begin{tabular}{|c|c|c|c|}
\hline \multirow[t]{2}{*}{ Itens avaliados } & \multicolumn{3}{|c|}{ Opinião dos clientes } \\
\hline & Irrelevante & Indiferente & Importante \\
\hline Equipamentos mais modernos & $39 \%$ & $39 \%$ & $22 \%$ \\
\hline Abrir aos finais de semana & $34 \%$ & $25 \%$ & $41 \%$ \\
\hline Climatização da academia & $38 \%$ & $29 \%$ & $33 \%$ \\
\hline $\begin{array}{l}\text { Alunos dispostos a pagar pelos } \\
\text { benefícios requisitados }\end{array}$ & \multicolumn{3}{|c|}{$33 \%$} \\
\hline
\end{tabular}

Ao analisar os resultados dessa última enquete, Eduardo entendeu que as reivindicações não eram compartilhadas pela maioria dos alunos e que as mudanças sugeridas não eram imprescindíveis ou tão importantes quanto a localização e 0 atendimento oferecidos por sua academia. Sendo assim, decidiu por manter o empreendimento exatamente da forma como estava, reforçando seu argumento ao afirmar que "raríssimas academias na região abrem aos finais de semana e nenhuma delas oferece sistema de climatização".

\section{CONCORRÊNCIA INESPERADA... E AGORA?}

A notícia da abertura de uma nova academia na cidade - uma nova concorrente - chegou de forma inesperada para Eduardo que, obviamente, reconheceu nela uma surpresa nada agradável. Um sentimento de preocupação com o futuro foi the deixando intrigado e pensativo, especialmente ao analisar com mais cuidado 0 
encarte da nova concorrente. Três questões principais chamavam a sua atenção na propaganda do novo empreendimento.

Primeiro, a sua localização: a concorrente seria inaugurada na mesma rua da Edu's, a menos de cem metros de distância. Ele havia observado a movimentação de operários durante a reforma de um imóvel - de aproximadamente $350 \mathrm{~m}^{2}$, pouco menor que a Edu's - que abrigara um antigo banco; mas não imaginava que ali seria o endereço de um empreendimento do seu ramo de negócios.

Segundo, percebeu que as inovações da nova academia (horários aos finais de semana, equipamentos modernos e ambiente climatizado) eram justamente os diferenciais que a Edu's não oferecia e que, portanto, seriam os atrativos da concorrente. Eduardo comprovou as novidades anunciadas, pela concorrente, ao passar pelo endereço da nova academia e observar os equipamentos de primeira linha e condicionadores de ar sendo descarregados de um caminhão.

Por fim, o que mais the deixou incomodado foi descobrir que o preço da mensalidade anunciado no encarte da concorrente $(R \$ 99,90)$ era praticamente o mesmo oferecido na Edu's $(R \$ 99,00)$. Ele imaginou que 0 valor anunciado pela nova academia poderia ser em caráter promocional e temporário para atrair clientes. Porém, não tinha como comprovar sua hipótese, tampouco saber por quanto tempo a proposta seria mantida, se era realmente uma estratégia de inauguração ou se o preço sugerido seria efetivamente comercializado pela nova academia.

Eduardo voltou para casa, procurou relaxar e analisar com cuidado o cenário que se desenhara. Ele estava diante de uma nova concorrente que, em breve, ofereceria mais do que a Edu's oferecia, pelo mesmo valor cobrado por ele e praticamente na mesma localização. Naquele momento, pensou nos seus clientes recebendo o mesmo encarte que recebera naquela manhã em sua casa e ficou imaginando o que cada um deles faria diante das propostas da nova academia. Acreditava que muitos de seus clientes, fiéis e confiantes no seu trabalho - principalmente os mais antigos -, permaneceriam na Edu's, independentemente da abertura da concorrente.

Eduardo confiava na qualidade do seu trabalho e no atendimento que oferecia aos seus clientes, mas não tinha ideia de quantos deles estariam dispostos a experimentar a nova academia. Afinal, a concorrência estava oferecendo "mais" pelo "mesmo preço". E se os clientes dele experimentassem a concorrente, será que trocariam de academia?

De olhos fechados, Eduardo refletiu por um instante sobre todo o trabalho realizado durante os anos à frente de seu empreendimento. Ser proprietário de uma academia era um sonho desde a sua juventude; nunca havia pensado em trabalhar com outra coisa. Tinha consciência de que administrara bem o seu negócio ao longo dos anos, prova disso era o sucesso alcançado; mas, de fato, nunca tinha enfrentado concorrentes diretos.

Ao abrir os olhos, teve uma única certeza: queria manter a integridade do seu empreendimento, mas não sabia ao certo o que fazer. Antes de qualquer atitude, pegou o celular do bolso e decidiu ligar para o filho na capital. O filho mais velho, como futuro administrador, deveria conhecer estratégias de como lidar com a concorrência que entrou no mercado sem avisar.

E se você fosse o filho de Eduardo, que estratégias recomendaria para a Edu's? 


\section{NOTAS DE ENSINO}

\section{Objetivos Educacionais}

Este caso foi construído para ser utilizado como ferramenta auxiliar de ensino, principalmente em disciplinas relacionadas à estratégia, na graduação e em cursos de pós-graduação lato sensu na área de Administração.

O enredo - a história do caso de ensino - propicia a reflexão e a discussão acerca de determinados conteúdos relacionados à estratégia, dentre os quais:

1) Estratégias competitivas genéricas;

2) Visão baseada em recursos (RBV).

\section{Fonte de dados}

Este caso de ensino é uma história fictícia, inspirado em experiências vividas por um dos autores no contexto da gestão de academias de ginástica. Não existe uma relação direta com uma organização específica, mas reflete - ou pode refletir - situações vividas por empresários e empresas do setor de academias espalhadas pelo país.

\section{Sugestão para um plano de ensino}

Este caso de ensino pode ser utilizado em uma sessão de, pelo menos, 90 minutos.

A sessão deve ser conduzida, preferencialmente, com alunos que já estejam familiarizados com alguns temas relativos à estratégia. Entre esses temas, as forças da indústria (análise estrutural de indústrias) propostas por Porter (1986). Esse conhecimento prévio é interessante, pois as estratégias genéricas propostas por Porter são arranjos/táticas organizacionais para construir uma posição sustentável no longo prazo com 0 intuito de defender-se das forças da indústria explicadas pelo autor.

O caso deve ser entregue aos alunos antecipadamente, para que façam uma leitura/estudo prévia ao debate em sala de aula e apreendam o assunto discutido.

Sugere-se que os primeiros quarenta minutos da sessão de ensino sejam utilizados para o debate do caso em pequenos grupos ( 3 ou 4 alunos). Nessa ocasião é importante que os estudantes procurem esclarecer eventuais dúvidas sobre 0 caso, dividir opiniões sobre a história narrada e busquem responder às questões sugeridas para o caso (ou outras questões que o professor acredite serem pertinentes).

Em seguida, é conveniente que aconteça um debate no grande grupo (toda a turma) e que, com a condução do professor, sejam confrontadas as opiniões e as respostas dos diferentes grupos anteriormente formados.

Para melhor fixação do tema explorado, ao final da sessão, é interessante que o professor conduza uma retrospectiva resumida do conteúdo teórico explorado e sua aplicação no caso analisado, sanando ainda eventuais dúvidas que tenham ficado sem respostas. 


\section{FUNDAMENTAÇÃO TEÓRICA}

\section{Estratégias Genéricas de Porter}

Segundo Porter (1986), existem três estratégias potencialmente bem-sucedidas que podem criar uma posição defensável no longo prazo em um indústria, ou seja, para superar outras empresas num determinado mercado.
1) Liderança no custo total
2) Diferenciação
3) Enfoque

A primeira estratégia genérica, de liderança no custo total, consiste em alcançar a liderança numa indústria por meio da busca do menor custo total de determinado produto ou serviço. Isso significa que uma empresa direcionada para esta estratégia deve ter como objetivo central a busca pelo menor custo do produto/serviço em relação aos seus concorrentes, entretanto, sem ignorar elementos ou atributos essenciais do artigo comercializado (PORTER, 1986).

A posição de liderança no custo total, segundo o autor, oferece vantagens e proteção em relação às forcas da indústria (compradores, fornecedores, novos entrantes, concorrentes e substitutos). Liderar no custo, entretanto, exige maior parcela de mercado, controle de custos rígidos e investimentos em tecnologia ou processos que colaborem com a redução total dos custos da empresa.

Liderar no custo total, na perspectiva de uma academia de ginástica, exige, por exemplo, buscar um aluguel menor que o da concorrência, equipamentos que precisam de menos manutenção, investir pouco em publicidade, reduzir gastos com salários apenas ao essencial, etc.

A diferenciação é a segunda estratégia genérica e, conforme explica Porter (1986), consiste em criar algo, no produto ou no serviço oferecido, que seja único em relação ao restante da indústria. A diferenciação pode estar em apenas um elemento, ou em vários atributos do produto/serviço, desde que isso seja percebido e valorizado pelos consumidores daquela indústria.

Ao contrário da estratégia de liderança no custo total, a diferenciação torna, algumas vezes, inviável a obtenção de uma grande parcela de mercado. 0 diferencial/a exclusividade do produto/serviço torna, no entanto, esta estratégia viável para obter retornos acima da média e também cria uma posição defensável, no longo prazo, para enfrentar as forças competitivas da indústria.

A terceira estratégia genérica é o enfoque. Ao utilizar-se desta estratégia, uma organização deve focalizar "um determinado grupo comprador, um segmento da linha de produtos, ou um mercado geográfico" (PORTER, 1986, p.52). 0 autor explica que, ao contrário das estratégias de baixo custo e de diferenciação, que visam explorar a indústria, o enfoque procura atender excelentemente apenas um determinado alvo.

Neste sentido, a estratégia de enfoque acaba atingindo a diferenciação, ou o menor custo - ou ambos naquele nicho específico, mesmo que não atinja em relação à indústria. A empresa com estratégia de enfoque terá o menor custo, ou o produto diferenciado para aquela determinada região geográfica, ou para aquele determinado grupo comprador.

Porter (1986) explica que uma organização que opte como estratégia o meio-termo, ou seja, tentar assumir ao mesmo tempo mais de uma estratégia, é uma atitude que em longo prazo não tende a ser sustentável. $\mathrm{O}$ autor acredita que é necessário tomar uma única estratégia como fundamental, pois a execução adequada de cada estratégia genérica exige recursos, virtudes, disposições organizacionais e estilo administrativo distintos.

Por fim, Porter (1986) esclarece sobre os riscos de assumir cada uma das estratégias genéricas. Essencialmente, esses riscos estão atrelados em não atingir com êxito a estratégia almejada, ou que a essência de determinada estratégia (menor preço, diferencial, ou enfoque) não seja valorizada pelos compradores da indústria. 


\section{Visão Baseada em Recursos (VBR)}

A Visão Baseada em Recursos (VBR) é a perspectiva teórica que considera, essencialmente, a influência dos recursos de uma organização no resultado que ela obtém na indústria em que está inserida (BARNEY, 1991; CARNEIRO; CAVALCANTI; SILVA, 1997 BARNEY, 2001).

Na VBR o fator decisivo para uma empresa obter desempenho acima da média são os recursos e a configuração dos recursos de uma empresa em comparação aos seus concorrentes (BARNEY, 1991). Não obstante, a obtenção de vantagem competitiva não é, segundo essa perspectiva, resultado apenas dos recursos que a organização possui, mas da criação, da aquisição e da disposição dos recursos para a obtenção de competências únicas, valiosas e que diferenciem a organização das outras empresas de uma indústria (BARNEY, 1991, 2001).

Segundo Barney (1991), a obtenção de vantagem competitiva acontece quando uma empresa possui recursos que as concorrentes não possuem. Nesta perspectiva, uma empresa obtém vantagens em relação à concorrência se os recursos que ela possui são importantes para o negócio da empresa, quando poucos concorrentes o possuem - ou nenhum -, quando os recursos não são facilmente imitáveis e quando não podem ser substituíveis por outros recursos de igual função.

0 autor explica que recurso deve ser entendido como todo o ativo (tangível ou intangível) que uma empresa dispõem e que pode ser utilizado para implementar as estratégias da organização. Neste entendimento, podem ser compreendidos como recursos de uma organização, por exemplo, equipamentos, matéria-prima, pessoas (que são recursos tangíveis), processos, conhecimentos, relacionamentos, capacidades, habilidades (que seriam entendidos como recursos intangiveis).

Ao contrário da análise da indústria proposta por Porter (1986), em que o principal determinante do desempenho das organizações é a configuração da indústria e as forças que interagem neste ambiente (externo à organização) - barreiras de entrada, rivalidade entre concorrentes, força de barganha dos fornecedores, força de barganha dos compradores e produtos substitutos -, a Visão Baseada em Recursos propõe um olhar interno do ambiente organizacional - para os recursos/competências (BARNEY, 1991).

Embora aparentem ser inicialmente contraditórias, a RBV e a Análise da Indústria de Porter podem ser entendidas como complementares (CARNEIRO; CAVALCANTI; SILVA, 1997). Segundo os autores, a análise da indústria propõe a apreciação do ambiente externo à organização - oportunidades e ameaças - e a RBV observa perspectiva interna - dos recursos - da organização. 


\section{Sugestões de questões para discussão do caso:}

1) Como você classificaria a estratégia utilizada, até então, pela academia de Eduardo e pelo novo concorrente? Considere a tipologia de estratégias genéricas proposta por Porter (1986).

$O$ empreendimento de Eduardo foi durante muitos anos a única academia a oferecer serviços na região central da cidade, o que poderia ser compreendido como uma estratégia de enfoque (ao atender a um determinado mercado geográfico). No entanto, a inexistência de concorrentes diretos na região em que a Edu's oferecia seus serviços propiciou, na verdade, a não adoção de uma estratégia definida, ou ainda, o emprego de uma estratégia meio-termo (quando não existe uma única estratégia, bem definida, que norteia a organização).

Por outro lado, a estratégia utilizada pela nova concorrente é a diferenciação. A estratégia pode ser percebida, pois a concorrente oferecerá vários diferenciais que a academia de Eduardo não oferece e que são valorizados pelos frequentadores de uma academia de ginástica (equipamentos modernos, horários atrativos, ambiente climatizado).

2) Elabore um quadro comparativo entre as características da Edu's e da nova concorrente. Evidencie, com os dados encontrados no texto, os diferenciais competitivos entre as concorrentes, listando os pontos fortes e fracos das duas academias?

\begin{tabular}{|l|c|c|}
\hline Característica & Edu's & Nova Concorrente \\
\hline Localização & Centro & Centro \\
\hline Estacionamento & Sim & Sim \\
\hline Mensalidade (R\$) & 99,00 & 99,90 \\
\hline Tradição & Sim & Não \\
\hline Espaço físico & $500 \mathrm{~m}^{2}$ & Aprox. 350m² \\
\hline Professores & Bem avaliados & $?$ \\
\hline Atendimento & Bem avaliado & $?$ \\
\hline Clientes matriculados & 300 (média) & $?$ \\
\hline Aluguel & R\$ 4.500,00 & $?$ \\
\hline Equipamentos & Em bom estado & Novos e modernos \\
\hline Final de semana & Fechada & Aberta \\
\hline Climatização & Não possui & Possui \\
\hline Panfleto de divulgação & Ausente & Ótimo \\
\hline
\end{tabular}

Fonte: Elaborado pelos autores.

3) Observando o quadro comparativo que você elaborou (questão 2) e considerando, ainda, questões como a "tradição" que a Edu's tem na região e os bons resultados obtidos nas pesquisas de satisfação com os clientes da academia: você acredita que a abertura da nova concorrente deve realmente ser motivo de preocupação para Eduardo? Por quê?

Sim, a abertura da nova concorrente deve ser atentamente considerada por Eduardo, pois a concorrente oferecerá diferenciais que a sua academia não oferece e que, de acordo com as pesquisa que ele mesmo realizou, são valorizadas pelos clientes.

Existe a possibilidade de que aproximadamente $30 \%$ dos clientes da academia de Eduardo - aqueles que responderam, na pesquisa, estarem dispostos a pagar mais para terem mais - sintam-se tentados a experimentar a academia que oferece os diferenciais que eles requisitavam na academia de Eduardo. Isso deve 
ser motivo de preocupação para ele, caso não queira ter o lucro de seu empreendimento diminuído no final de cada mês.

4) Considerando a abertura iminente da nova concorrente, seria interessante que Eduardo investisse, neste momento, em seu empreendimento (climatizando o ambiente, modernizando os equipamentos e/ou abrindo aos finais de semana) para que pudesse competir com igualdade com a nova academia? Justifique.

É verdade que a nova academia oferecerá diferenciais que a academia de Eduardo não oferece e, assim sendo, é provável que alguns clientes busquem na concorrência aquilo que gostariam de ter e que a Edu's não oferece.

Entretanto a academia de Eduardo possui características/qualidades que a nova concorrente não pode, antecipadamente, garantir (como o bom atendimento e a qualidade dos professores). Como, em teoria, esses atributos são considerados importantes na prestação dos serviços de uma academia, é cabível acreditar que muitos clientes simplesmente não "troquem o certo pelo duvidoso", ou seja, permaneçam na Edu's. É o "custo de mudança", que acontece quando um cliente está habituado com um determinado serviço e tende a permanecer com o mesmo fornecedor, é um elemento a favor do empreendimento de Eduardo.

Os custos para equiparar o empreendimento de Eduardo ao novo concorrente são elevados e, assim, pode ser: primeiro, arriscado investir uma grande quantia de dinheiro no empreendimento para apenas igualar-se ao concorrente e; segundo, desnecessário, caso poucos clientes demonstrem interesse em migrar para a nova academia.

Assim, a tentativa de igualar-se ao concorrente talvez não seja, inicialmente, uma boa ideia para o empreendimento de Eduardo.

5) Suponha que, de fato, após a abertura da nova academia, Eduardo perceba a migração de uma considerável parcela de seus clientes para a nova concorrente ( $45 \%$ dos clientes, por exemplo). Que estratégia(s) seria(m) recomendada(s) para o empreendimento de Eduardo? Essa(s) estratégia(s) poderia $(m)$ evitar que a migração de clientes acontecesse?

Com a abertura de uma nova concorrente é muito provável que a atual participação de mercado da academia de Eduardo diminua, o que é quase inevitável diante da abertura de um novo player no mercado.

Caso os clientes da Edu's percebam que os benefícios (os diferenciais) oferecidos pela nova academia sejam maiores que os benefícios oferecidos pela academia de Eduardo, e que as mensalidades exercidas sejam equivalentes ou muito parecidas, pode acontecer uma migração de clientes.

Neste caso, imaginando que Eduardo optou por não equiparar sua academia à concorrente e diante dos diferenciais que a concorrência está oferecendo, talvez seja interessante que a Edu's assuma a estratégia genérica de liderança no custo total, proposta por Porter (1986). Neste sentido, o empreendimento de Eduardo optaria por não oferecer os diferenciais que o concorrente proporciona, todavia buscaria o menor custo de prestação de serviços e, consequentemente, exerceria um preço menor que o da concorrência. Ao assumir uma estratégia de liderança no custo e com a diminuição do valor da mensalidade da Edu's, é possível acreditar que a academia de Eduardo ganhe novos clientes.

Por outro lado, entendendo que a estratégia de diferenciação pode assumir muitas formas diferentes (para mais detalhes leia Estratégias Genéricas, MINTZBERG, 2006), Eduardo poderia pensar em manter o valor da mensalidade da sua academia (ou até aumentá-lo), caso criasse algum(s) diferencial(ais) - valorizado(s) pelos clientes - que o concorrente não fosse ou pudesse oferecer.

O próprio relacionamento que os clientes de Eduardo têm com ele e com os funcionários e professores da academia poderia, por exemplo, ser trabalhado como diferencial em relação ao novo concorrente. Aulas criadas na própria academia de Eduardo, atendimento especial para mulheres ou para a terceira idade, descontos de acordo com o tempo de fidelidade do cliente, também são diferenciais que poderiam ser oferecidos na Edu's. 
6) Fundamentando-se na Visão Baseada em Recursos (VBR), você acredita que a climatização, a modernização dos equipamentos e a abertura da academia aos finais de semana seriam diferenciais interessantes para a Edu's antes que uma concorrente entrasse no mercado oferecendo esses diferenciais?

É provável que sim. Com base na informação que o próprio Eduardo tinha, de que "raríssimas academias" na região abriam aos finais de semana e "nenhuma" oferecia ambiente climatizado, a Edu's tinha a oportunidade de oferecer diferenciais que outras academias não tinham e que eram: valorizados no negócio da empresa (os clientes requisitavam os diferenciais e uma parcela estava disposta a pagar por isso); raros, pois poucas academias abriam aos finais de semana e nenhuma oferecia climatização; difícil de serem imitados, pois o investimento para climatizar o espaço de uma academia é relativamente alto; e insubstituível, pois os benefícios de ventiladores ou umidificadores não proporcionariam o mesmo bem-estar que um ambiente climatizado oferece.

Ainda que fosse complicado criar todos os diferenciais que os clientes requisitavam, com base na enquete realizada com seus clientes, Eduardo poderia identificar as demandas mais valorizadas por eles. Assim, teria condições, por exemplo, de proporcionar a abertura da academia nos fins de semana (exigência que demandaria provavelmente o menor investimento e que era requisitado por $41 \%$ dos clientes); e/ou instalar a climatização do ambiente, visto que nenhuma academia na região oferecia este diferencial valorizado por $1 / 3$ dos seus clientes.

Com o ambiente climatizado, a Edu's teria um recurso que a diferenciaria drasticamente de outras academias da região. 0 empreendimento de Eduardo obteria, então, uma vantagem competitiva em relação aos seus diversos concorrentes, pois teria a posse de um recurso que é valioso, raro, difícil de ser imitado e complexo para ser substituído.

\section{REFERÊNCIAS}

BARNEY, J. Firm resources and sustained competitive advantage. Journal of Management, v.17, p.99-120, 1991.

BARNEY, J. Resource-based theories of competitive advantage: a tem year retrospective on the resource-based view. Journal of Management, v. 27, p 643-650, 2001.

CARNEIRO, J.M.T.; CAVALCANTI, M.A.F.D.; SILVA. J.F. Porter revisitado: uma análise crítica da tipologia estratégica do mestre. Revista de Administração Contemporânea, vol. 1, n. 3, 1997.

PORTER, M. Estratégias Competitivas Genéricas. In: Estratégia Competitiva: técnicas para análise de indústrias e da concorrência. Rio de Janeiro: Campus, 1986. Cap. nº 2, p.49-60.

\section{LEITURAS COMPLEMENTARES}

MINTZBERG, H; Estratégias Genéricas. In: MINTZBERG, H; LAMPEL, J; QUINN, J.B.; GHOSHAL, S. 0 processo da estratégia: conceitos, contextos e casos selecionados. 4. ed. Porto Alegre: Bookman, 2006. Cap. 4.5. 2006.

PORTER, M. Análise Estrutural de Indústrias. In: Estratégia Competitiva: técnicas para análise de indústrias e da concorrência. Rio de Janeiro: Campus, 1986. Cap. n 1, p.22-48. 